\title{
DEVELOPMENT OF AN OVERALL FUNCTIONAL PROCESS UTILIZING 3D DATA MODELS AND AUTOMATION FOR REHABILITATION OF ROAD STRUCTURES - CASE VT4, HAURUKYLÄ-HAARANSILTA (3D-ROAD)
}

\author{
Rauno Heikkilä \\ University of Oulu, Finland \\ rauno.heikkila@oulu.fi \\ Teemu Kivimäki \\ University of Oulu, Finland \\ teemu.kivimaki@oulu.fi \\ Ty A. Lasky \\ University of California - Davis, CA USA \\ talasky@ucdavis.edu
}

\begin{abstract}
The paper introduces the main results of a large R\&D project called 3D-ROAD carried out 2006-2009 in Oulu, Finland. The primary objective of the project was to develop a 3D functional process for enhancing road structures, utilizing automation, and improving the efficiency and quality of the measuring, design and construction processes. The fundamental idea of automated road rehabilitation is to measure, design and execute all of the various possible work tasks using 3D techniques to create, transfer, and utilize continuous information models throughout the entire working process. This process can work if each of the tasks can be performed accurately, reliably, and economically. Measured 3D initial data models enable the optimization of road structures in the road design phase and continuous 3D structure and machine control models with 3D machine guidance for efficient execution of construction. All of the essential information can further be transferred and utilized during later maintenance phases.
\end{abstract}

\section{KEYWORDS: 3D, automation of road construction, rehabilitation}

\section{INTRODUCTION}

\subsection{Background}

The main emphasis in road construction in industrialized countries will increasingly be on the area of maintenance and repair. The process for road reconstruction or structural rehabilitation differs in many respects from new road construction. The main difference is that in the former case, roads will not be designed and constructed to run through undeveloped areas - instead, the initial situation will involve existing road geometry with all associated structures, materials, and equipment. The aim of structural rehabilitation is to repair any detected damage utilizing existing structural parts and materials wherever possible. So far, geometric control in the structural rehabilitation process has, in most cases, been 
based on the road's longitudinal geometry (linear referencing systems, or LRS). Typically, the use of 3D geodetic coordinate systems has been limited to single cases.

Emerging techniques offer new possibilities for improvement of the road rehabilitation process. For example, Saarenketo (2006) has studied the applicability of GPR method in road construction and the development work is already completed. Until now, the emphasis in 3D GPR method development work has been on the measurement of basic observable quantities. With the exception of individual experiments, 3D surface and volume data has not been taken into account in the product design phase.
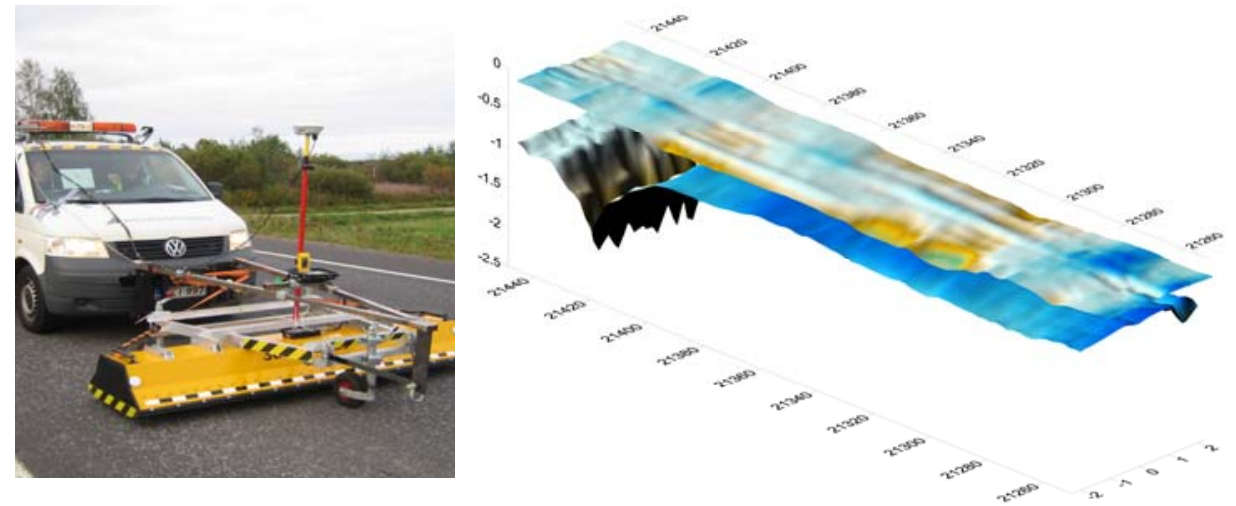

Figure 1. Road surface and base layer data acquired using a 3D GPR scan of the road structure (left), experimentally converted into a 3D initial data model (right).

Also the rapid development of laser scanning technologies has continued in recent years. In Finland, the terrain modeling phases of large new road construction projects are today almost exclusively carried out using helicopter-based laser scanning. Ground vehicle-based laser scanning methods have also been studied and developed in different parts of the world. ALEngineering Oy has been developing a Finnish laser scanning system for a number of years in co-operation with University of Oulu. The objective of this development work has been to produce an efficient, accurate, and very inexpensive measuring system for road and street surfaces. The system has not yet been applied in measuring the initial data used in the structural rehabilitation process.

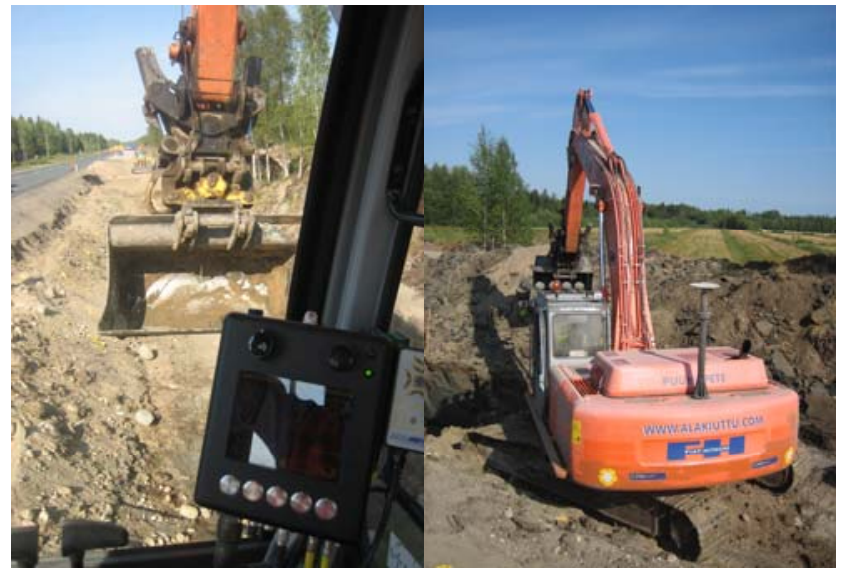

Fig. 2. An on-site experiment in structural rehabilitation involving a 3D-controlled excavator equipped with the new GNSS receiver (University of Oulu, 2006). Effective and precise use of 3D control systems in structural rehabilitation projects requires that the work process be based on precise 
rehabilitation plans targeting damage detected during the continuous initial 3D data measurement process, using a machine control model based on the plan.

The machinery utilized in the implementation of the structural rehabilitation is in part identical to that used in new road construction (excavators, graders, earth-hauling trucks, wheel loaders, compacting machines, etc.), but also includes special equipment specifically developed for the purpose. The working methods differ somewhat from those associated with new road construction-typically, they are geared towards the re-use of old structures and materials wherever possible. Successful processing of the data acquired from the early product design and initial data measuring processes into continuous 3D machine control models is critical for enabling the implementation of machine automation in the structural rehabilitation process. All phases must be based on the use of continuous 3D data models. It is also possible, at least in principle, to utilize wireless functional control systems to control and optimize the implementation of the structural rehabilitation. The methods and functions typically used in measuring actualized data and implementing quality control consist in part of those used in the initial data acquirement (3D laser scanning, 3D GPR) but can also include actualized data measuring functions connected to the construction machines' 3D control systems, as well as other methods of measurement.

In the research area of construction automation and robotics, there are surprisingly few studies on the use of automation in the rehabilitation of road structures.

\subsection{Objectives}

The main objective of the 3D-ROAD research project was to develop a 3D functional process for enhancing road structures, utilizing automation, and improving the efficiency and quality of the measuring, design, and construction processes.

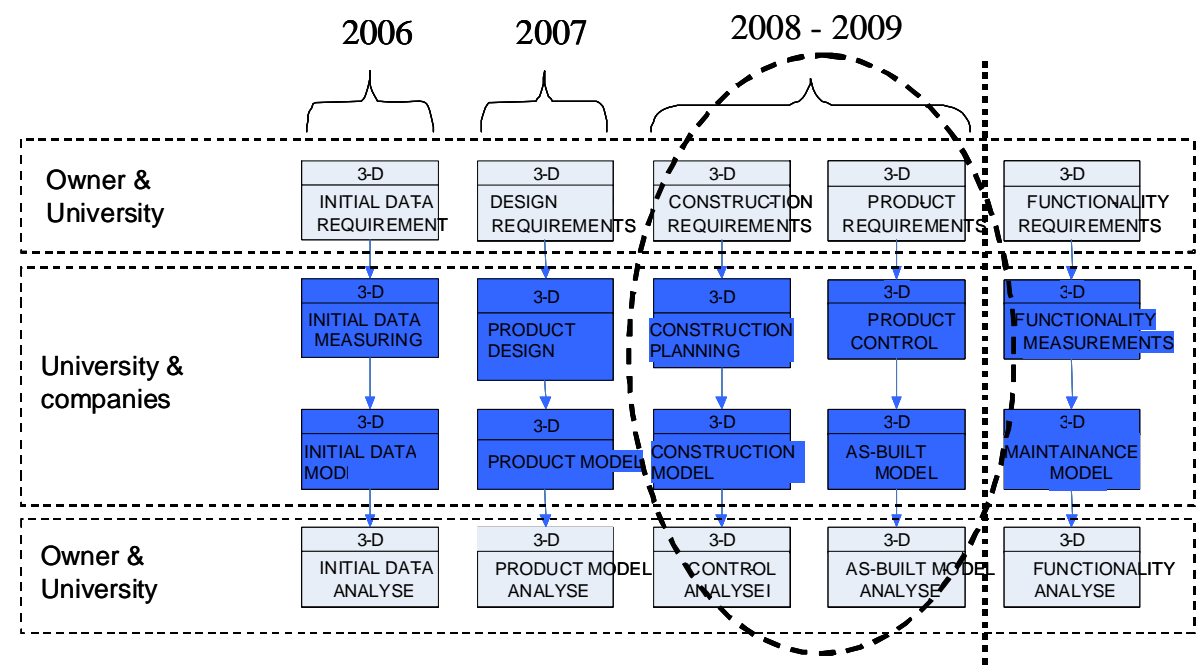

Fig. 3. Development of the total process in the collaboration with owner, technology providers, surveying consultants, design consultants, researchers, and contractors.

The partial objectives enabling achievement of the main objective were: 
- to complete the research tasks required for the development of an overall functional process;

- to model the overall functional process in order to complete a full-scale test project;

- and to complete an experimental implementation of automation, i.e. the overall functional process, in an actual construction project.

The Finnish Road Administration (FRA) also participated in the research project in cooperation with the University of Oulu, aiming to develop subphase-specific requirements to speed up the implementation of new technology as part of the 3D-ROAD project. The requirements were to be included in the requests for bids, enabling the actors to present their own implementation solutions as part of their bids. The test project gave the companies an opportunity to develop and test automation technology. The common objective of the University of Oulu and the FRA was to complete the construction on the actual test site, setting a global standard in utilization of progressive 3D automation. The project was completed using the best technology and skills currently available. The first aim was to get the companies to start developing their automation technology. The second aim was to acquire more comprehensive and accurate initial data utilizing accurate 3D positioning. The third aim was to design and model new 3D road geometry as part of the structural rehabilitation project. The fourth aim was to utilize 3D machine control in the construction of the pilot project.

\section{DEVELOPMENT OF 3-D ROAD REHABILITATION PROCESS}

For the experiments, a real road rehabilitation project - total length $12.5 \mathrm{~km}$, budget about 3 million eur, including road widening work, structural improvements, and paving-was provided by the owner (Finnish Road Administration). The main task of the University of Oulu was to develop, model, and determine the total process for road rehabilitation work and suggest different technologies, methods, means of information transfer, tools, and other skills needed for the experimental part of the project. For the execution of the different main work phases, different companies were selected through market competitions arranged by the owner.

\subsection{Initial Data Surveying}

According to the national recommendation in Finland, (JHS 154) EUREF-FIN coordinate system with Gauss-Kruger (ETRS-GK25) projection as well as N60 height reference system were selected and used in the project (JHS154). The more accurate base points were first built and measured using $4 \mathrm{~km}$ intervals between points. A site reference point network using $300 \mathrm{~m}$ maximum interval between each points was measured and built into the construction site area. In the practical work, the points were constructed first. After this, the GPS measurements were performed using Javad GPS devices for the determination of the coordinates for each point. Both GPS and GLONASS satellites were utilized. 


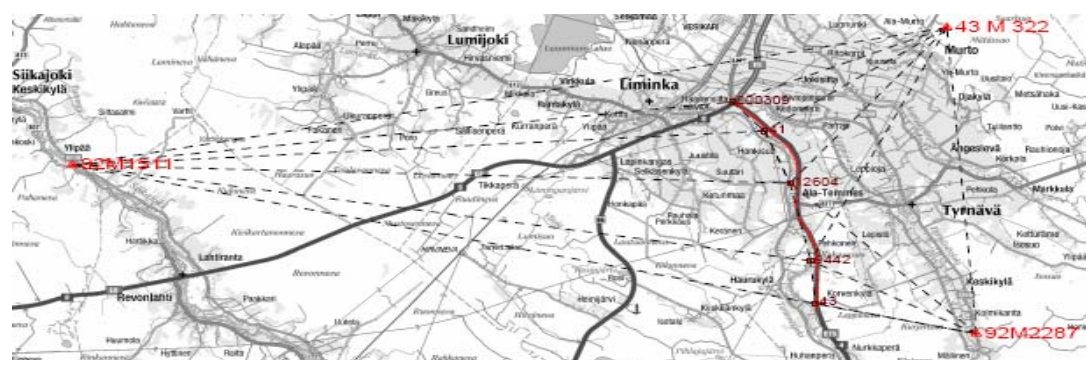

Fig. 4. The reference points used for determination of the site points (IV class national reference point network).

The calculations were made in two major phases. First, the main reference points of $4 \mathrm{~km}$ intervals were calculated to vectors and then an adjusted using least squares optimization in the WGS84 coordinate system. Finally, the coordinates and residuals were calculated through 7-parameter coordinate transformation into the EUREF-FIN coordinate system.

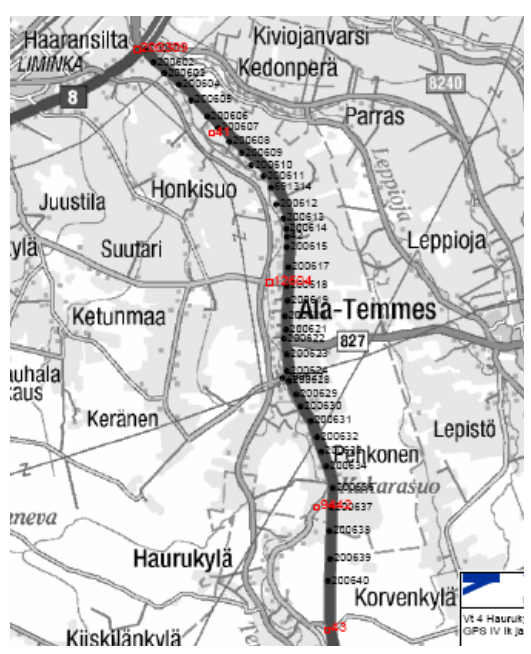

Fig. 5. Site reference points.

In 2005, different traditional initial data measurements were done in the site area. In addition to these, new 3D GPR (Ground Penetrating Radar), 3D helicopter-based laser scanning, and 3D ground-based mobile laser scanning measurement were done. A new wave form analysis method was tested in the helicopter measurement. The mobile laser scanner system was gereferenced using both total station and GNSS measurement methods. Additional reference measurements were executed using total stations. Three reference models each having $1 \mathrm{~km}$ length were measured to check the accuracy of measurement of the digital terrain model. 


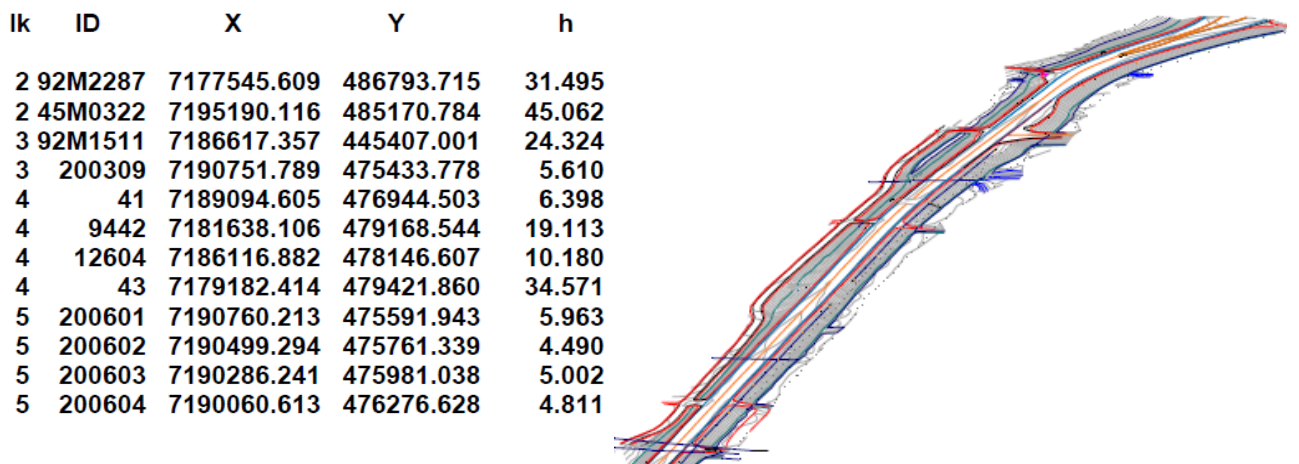

Fig. 6. Examples of the coordinates of the reference points (left) and the reference model (right).

The helicopter laser scanning was executed using two different flying altitudes (100 $\mathrm{m}$ and $200 \mathrm{~m}$ ). Flight \#1 was at $100 \mathrm{~m}$, flight \#2 was at $200 \mathrm{~m}$, and flight \#3 was at $200 \mathrm{~m}$ and used the new waveform technique. The aim of the waveform analysis was to detect different signals reflected from ground surface, trees, or leafs. The mobile laser scanning using a total station for geo-referencing of the system was made for a $1 \mathrm{~km}$ long road section in the Northern part of the site. In addition, the whole length of the road site was measured using the RTK-GNSS system for vehicle positioning. VRS (Virtual Reference Station) mode was used. The GPR measurements were performed using RTK-GNSS for positioning the system. The measurements were made at night time during low traffic periods. Four different measurement lines were used. The grid of $7.5 \mathrm{~cm}$ was used for the measured points. The observations were processed and analyzed using the RoadDoctor software developed by Roadscanners Oy. In all, 25 soil core drillings were made by another company to have reference points for the checking of the accuracy of GPR measurements. The results were transformed and transferred to the road design software.

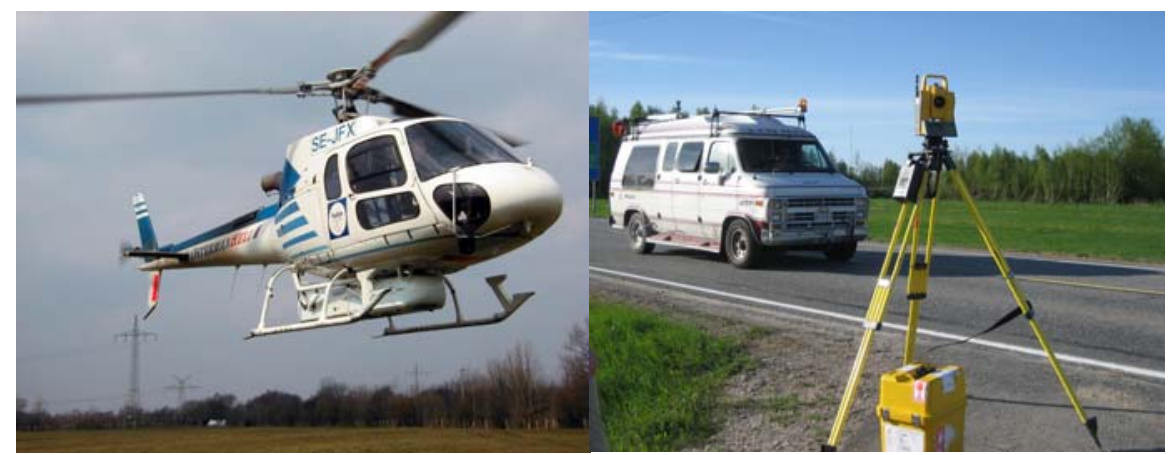

Fig. 7. The digital terrain model was measured by a helicopter laser scanning system (left) and a mobile vehicle based laser scanning system (right). 


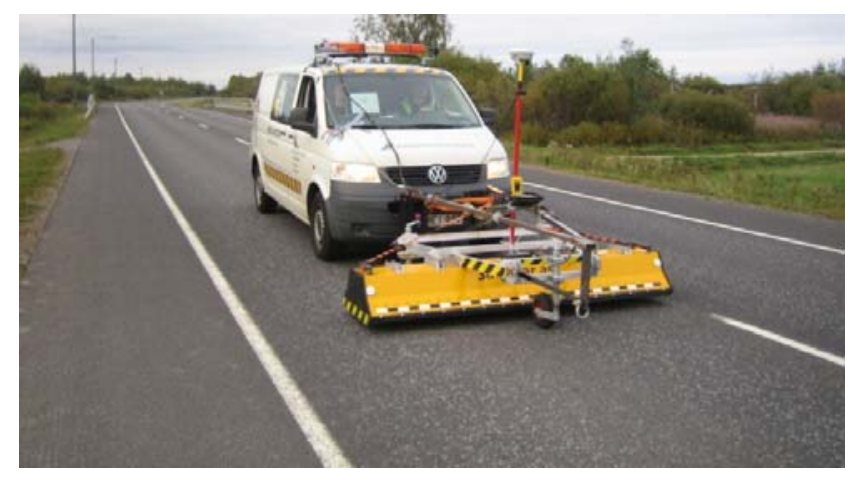

Fig. 8. 3D GPR measurement system.

\subsection{Road Design}

The first phase of the experiments in general road design phase was to transfer all of the measured 3D data into the road design software. Two different road design software packages were tested: Xstreet developed by Tekla Corporation, Finland; and Novapoint developed by Vianova Systems Corporation, Norway. The aim of the experiment was to test how the initial 3D data can be transferred into the road design software in question, how well the continuous 3D road model and additional machine control models can be designed and how the final quality of the machine control models can be checked using the different tools of these design software packages. The final aim of the experiments was to test how and in what format to transfer these machine control models to 3D machine control systems. The conclusions of the quality of the machine control models were made using machine control software (Landnova, developed by Novatron Oy, Finland) as a testing tool. A virtual model of the road was also produced for the simulation needs for the customer meetings, specifically for presentation to public residents in the road area.

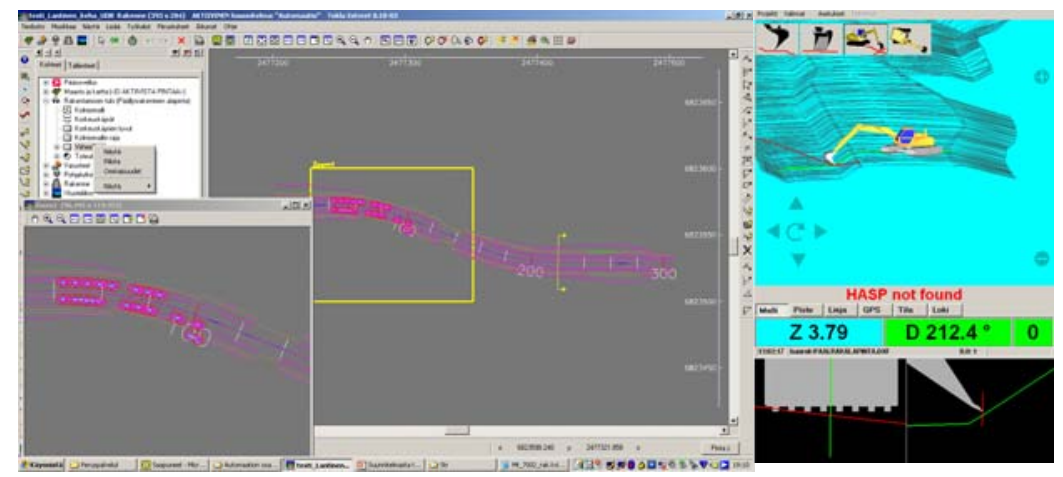

Fig. 9. 3D Road Design (Xstreet, Tekla Corporation): left picture introduces the removal of wrong points and lines, right the test of the 3D model in a machine control system (Novatron Oy). 


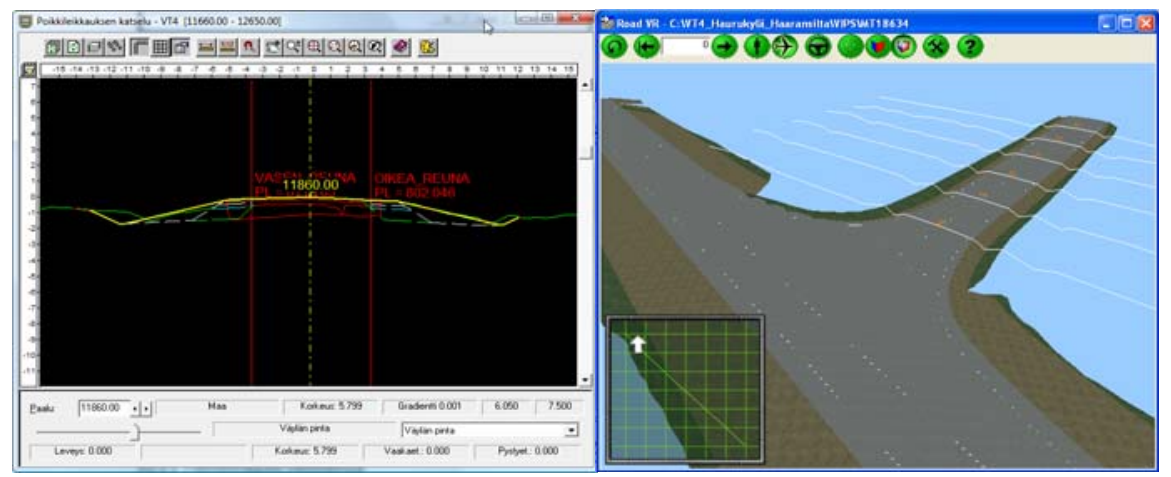

Fig. 10. A test of 3D Road Design: left a cross section including the 3D measured data of the old road structure, right examining visually the 3D road model (Novapoint, Vianova Systems Finland Oy).

\subsection{Design-Build}

More accurate structural road design based on the earlier general design was first made by the design office of the contractor Maarakennus Jaara Oy, which won the Design-Build market competition. All of the different 3D initial data was tested for use in this work phase. In the project, the contractor purchased and installed four 3D machine guidance systems into their excavators. This contractor had not previously utilized 3D machine control systems in their road works. The machine control models were created by the design consultant using point and line modelling. On site, the contractor used 3D-Win software to triangulate the models, and then executed a special quality control for the machine control models before delivering them to the machines via USB memory stick.

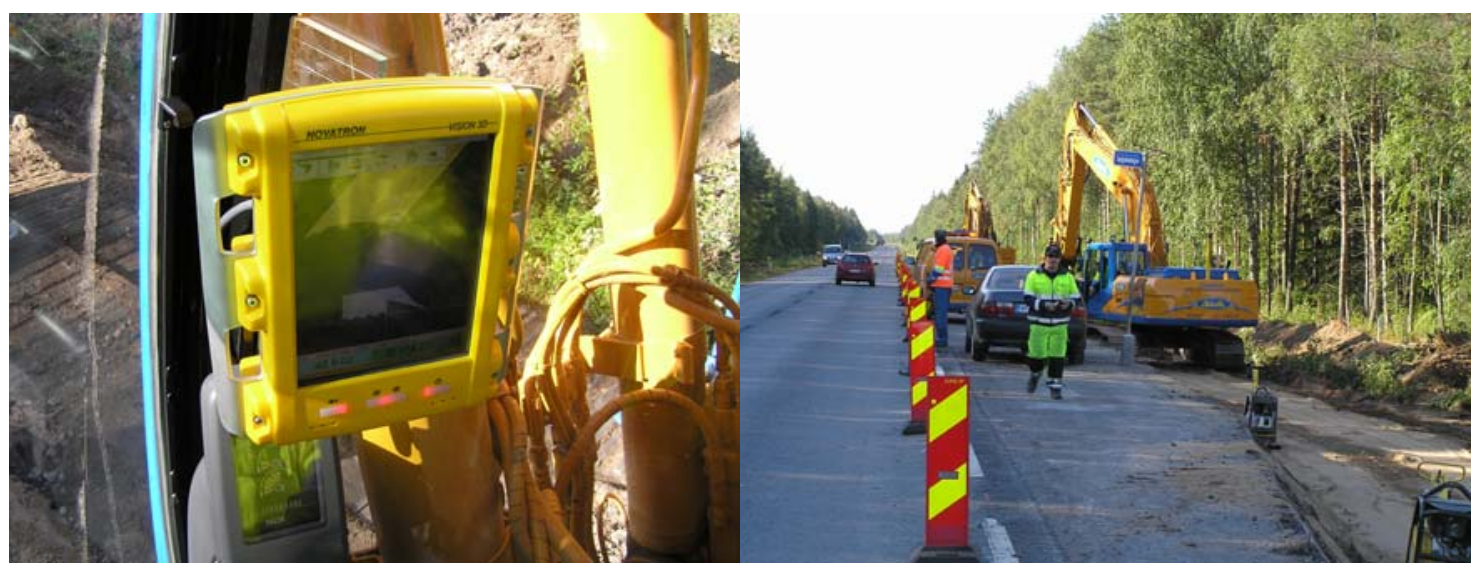

Fig. 11. Construction works using 3D machine guidance systems developed by Novatron Oy, Finland.

\subsection{As-Built Measurements}

A special As-Built feature and tool was included into the 3D machine control system used. During the construction work, the contractor made some tests with the tool. In addition, the 
contractor ordered a vehicle-based laser scanning measurement for the accuracy control of the final asphalt surface. In the measurement, a Stop \& Go laser scanning system developed by Mitta Oy, Finland, was used. Also a 3D GPR measurement (Roadscanners Oy) was executed after completing the construction activities.

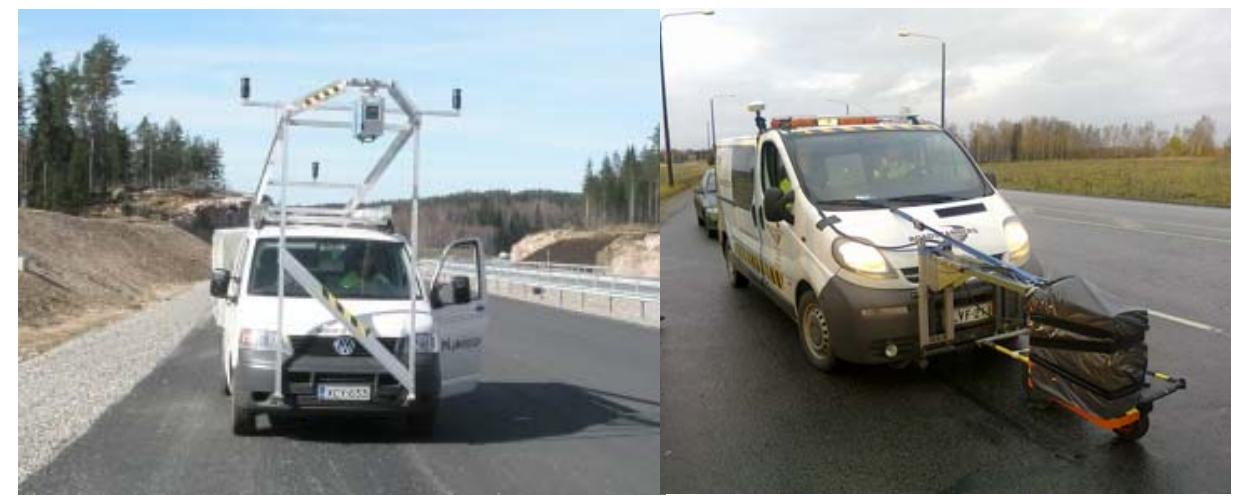

Fig. 12. The 3-D As-Built measurement systems used: left mobile laser scanning system, right GPR measurement system.

\subsection{Maintenance}

The possibilities of 3D techniques in the road maintenance phase were determined from another project, i.e., the Design-Build-Operate-Maintenance life cycle project (TYL-E18) operated by a joint venture company in Southern Finland. The annual geometric measurements and the quality control of the asphalt surface of each lane have been measured using the Stop \& GO laser scanning system by Mitta Oy.

\section{RESULTS}

\subsection{Results of Initial Data Surveying}

The photogrammetric images and the 3D point clouds measured by the helicopter-based laser scanning system were found to be very useful in the road design phase. The accuracy of the laser scanner point cloud (total 1,037,760 points over 240 hectares, or 4,324 points/hectare) on the old road surfaces was very high (deviation in vertical direction less than $\pm 2 \mathrm{~cm}$ ). The accuracy of measurement on other ground areas beside the road was worse, i.e., the average was $0.011 \mathrm{~m}$, with maximal deviation $0.902 \mathrm{~m}$, and there were $5.34 \%$ observations which had more than $0.025 \mathrm{~m}$ deviations compared to the reference measurements. The quality of the photogrammetric images was very good. 


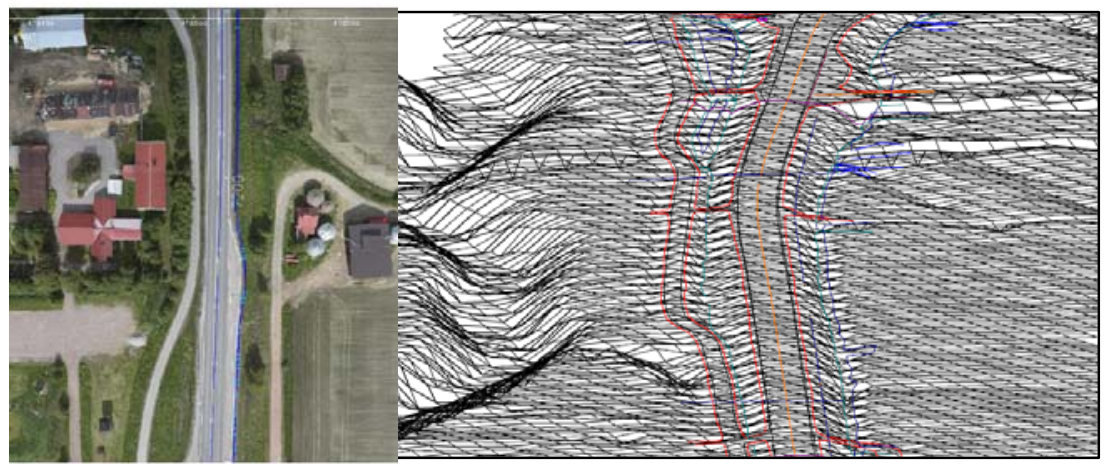

Fig. 13. A digital image (left) and a view to the DTM taken from the helicopter.

The images and point clouds measured from the helicopter were very information rich and in principle they could enable the later road design to be performed in many different ways. However, this is not yet possible presenting existing road design software. The basic problem was the too large size of point cloud; as such, the information model needed to be significantly diminished by decreasing the density of points, i.e., removing points from the point clouds. For example, any points of the trees and buildings were removed from the observations. The final amount of the points transferred to the road design software was only 700 points/hectare with $3.8 \mathrm{~m}$ average distance between points. It was not possible to rotate the model or work with the 3D point clouds or models in the user-interface of the road design software.

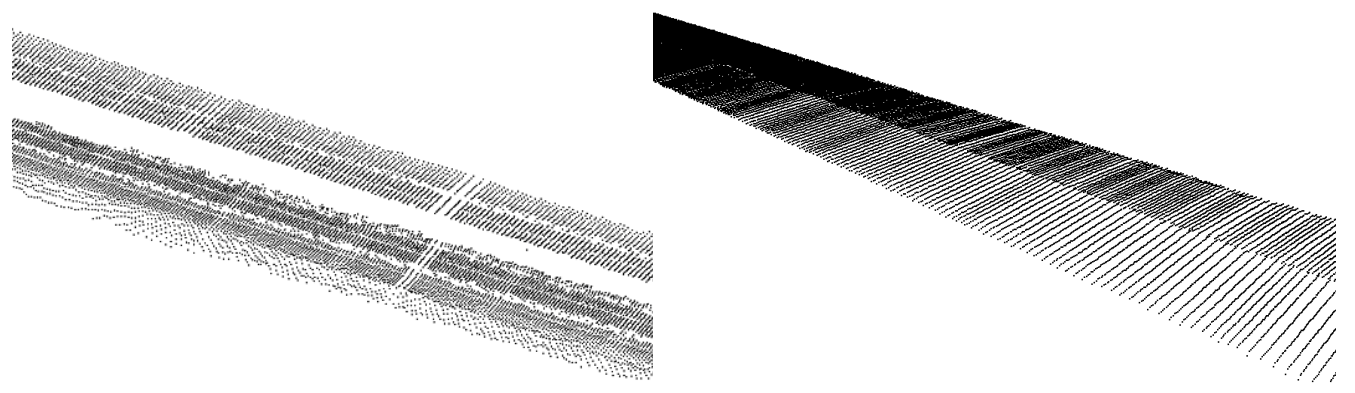

Fig. 14. Point clouds of the mobile laser scanning system using different positioning methods tested: the GNSS (left) based measurement and total station based one (right).

The accuracy of the mobile laser scanning measurement positioned using a total station method was $-0.0037 \pm 0.027 \mathrm{~m}$ (average \pm standard deviation) including all of the measurements. Maximum distance from the total station to the vehicle during measurements was $150 \mathrm{~m}$. The speed of the vehicle was less than $10 \mathrm{~km} / \mathrm{h}$. The measurement speed was $2 \mathrm{~km} /$ work day.

The worst accuracy of the mobile laser scanning measurement positioned using a GNSS system was $-0.0878 \pm 0.1045 \mathrm{~m}$ (average \pm standard deviation) including all of the measurements. The worst accuracy of the mobile laser scanning measurement positioned using a GNSS system was $-0.0295 \pm 0.0325 \mathrm{~m}$ (average \pm standard deviation) including all of the measurements. The measurement speed was $50 \mathrm{~km} /$ work day. 
The 3D GPR system measured a total of 12 GB raw data. This measured information model included 3D points of the $12.8 \mathrm{~km}$ road length having the point interval $7.5 \mathrm{~cm}$, antenna interval $7.5 \mathrm{~cm}$, i.e., 20 million measured observations (xyz points). After analysis by Roaddoctor software, the final amount of the interpreted points was 60-80 million. The points were delivered to the road designer using $1.0 \mathrm{~m}$ x $0.15 \mathrm{~m}$ grid. The differences between the 3D GPR measurement results and the references are presented in Tab. 1 and Tab. 2.

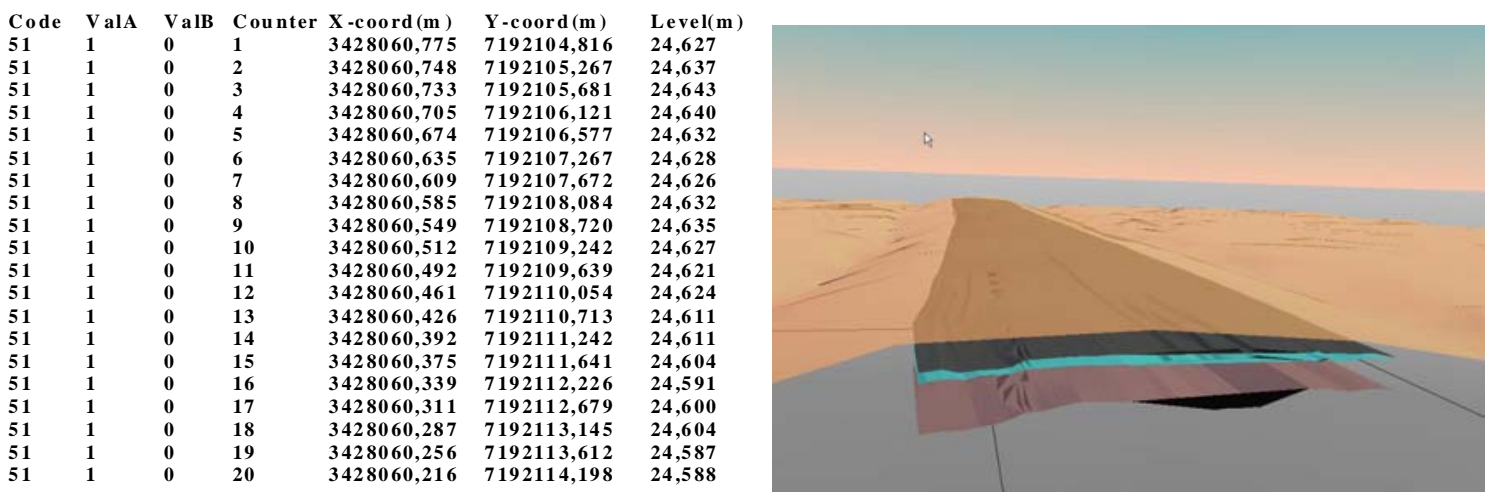

Fig. 15. The input format (left) developed and used for the transfers needed between GPR analyze software (RoadDoctor, Roadscanners Oy) and Road Design software (Xstreet, Tekla Oy). A view to the transferred 3D GPR data (right).

Tab. 1. The differences of the height levels between the 3D GPR and the traditional soil boring results.

\begin{tabular}{lccccc}
\hline Structural layer & $\begin{array}{c}\text { average } \\
{[\mathrm{m}]}\end{array}$ & $\begin{array}{c}\text { stdev } \\
{[\mathrm{m}]}\end{array}$ & $\begin{array}{c}\min \\
{[\mathrm{m}]}\end{array}$ & $\begin{array}{c}\text { max } \\
{[\mathrm{m}]}\end{array}$ & $\begin{array}{c}\text { range } \\
{[\mathrm{m}]}\end{array}$ \\
\hline lower surface of asphalt coarse & -0.057 & 0.030 & -0.102 & 0.002 & 0.104 \\
lower surface of base course & -0.043 & 0.182 & -0.318 & 0.451 & 0.769 \\
lower surface of sub-base layer & 0.027 & 0.315 & -0.636 & 0.846 & 1.482 \\
\hline
\end{tabular}

Tab. 2. The differences of the thicknesses between the 3D GPR and the traditional soil boring results.

\begin{tabular}{lccccc}
\hline Structural layer & $\begin{array}{c}\text { average } \\
{[\mathrm{m}]}\end{array}$ & $\begin{array}{c}\text { stdev } \\
{[\mathrm{m}]}\end{array}$ & $\begin{array}{c}\min \\
{[\mathrm{m}]}\end{array}$ & $\begin{array}{c}\text { max } \\
{[\mathrm{m}]}\end{array}$ & $\begin{array}{c}\text { range } \\
{[\mathrm{m}]}\end{array}$ \\
\hline pavement (asphalt) & 0.057 & 0.030 & -0.002 & -0.102 & 0.104 \\
base coarse & 0.014 & 0.186 & -0.510 & 0.320 & 0.830 \\
sub-base layer & -0.063 & 0.347 & -0.848 & 0.565 & 1.413 \\
total thickness of the layers & -0.003 & 0.312 & -0.846 & 0.636 & 1.482 \\
\hline
\end{tabular}

\subsection{Results from the road design phase}

The continuous 3D modelling requirement was found to be a new working task for the road designers in the project. The designers were, however, very experienced in traditional methods. They had never previously designed 3D machine control models. The main phases of road design were to input measured data, plan horizontal and vertical road geometry, create cross-sections for each of the road parts, and fit the structures to the digital terrain model and underground measured information. In the research, a primary focus was how to create 3D machine control models from the road model. The creation of 3D machine control models was successful without any more serious problems with both of the road design 
software packages. Additional work time was significant for the 3D modelling and finalizing work phases. Several different development possibilities were however observed, and these will be investigated in future research.

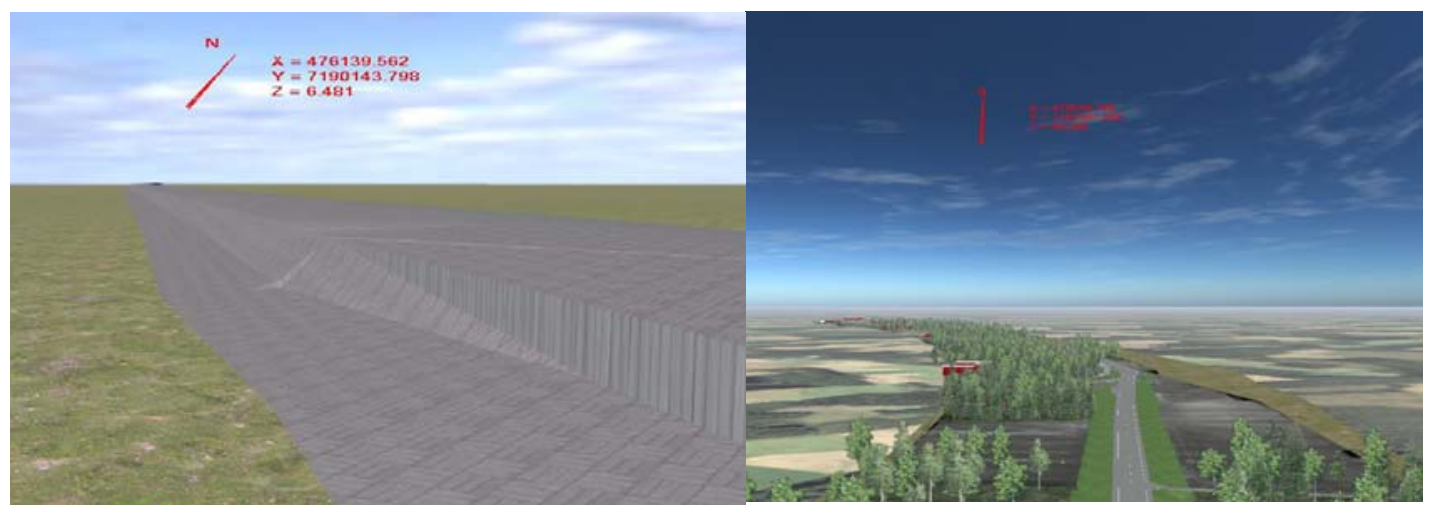

Fig. 16. Analyzing the 3D constructability of the structural layers (left), a scene to the virtual model (right).

The final quality of the continuous road model created by Xstreet road design and Novapoint software was evaluated to be sufficient for the machine control modeling phase. Road models created by both software packages remain to have some discontinuity parts in the models, which need to be manually corrected. Any of the initial data as well as the road structures are located in the database of the road design software. Hence, it was concluded that the task of machine control modeling needs to be performed inside the road design. This also eliminates later unnecessary checking and remodeling works by the site personnel. For the machine control modeling, additional design work of 1 workday $/ \mathrm{km} /$ surface was needed (Xstreet). No changes were observed in different information transfers performed.

No special problems in the handling of initial measured data were reported when using Novapoint road design software. The creation of road and machine control models was successful. Several development possibilities of the user interface of the Novapoint software were detected. One of these was to add new selection possibilities of different objects. Also the measured data should be able to be changed and selected directly from cross-section window. One development possibility was detected related to the connection of old measured structure and new structure. So the adaption methods and possibilities of new and old structure should be added and developed.

\subsection{Results of the Design-Build Phase}

With the beginning installation and starting phase complete, the 3D machine control systems worked well throughout the main construction phases. No special efficiency improvements were measured, but the contractor reported on several other benefits they detected from the $3 \mathrm{D}$ guidance of the machines. One of the most important observations was that the contractor, despite of the demand for only two 3D guidance systems in the machinery used on site, decided to purchase two additional systems for the site. This indicates there was a very good learning process and that the 3D guidance benefits were undeniable. A planned experiment with asphalt paving process was not realized due to limited resources. 


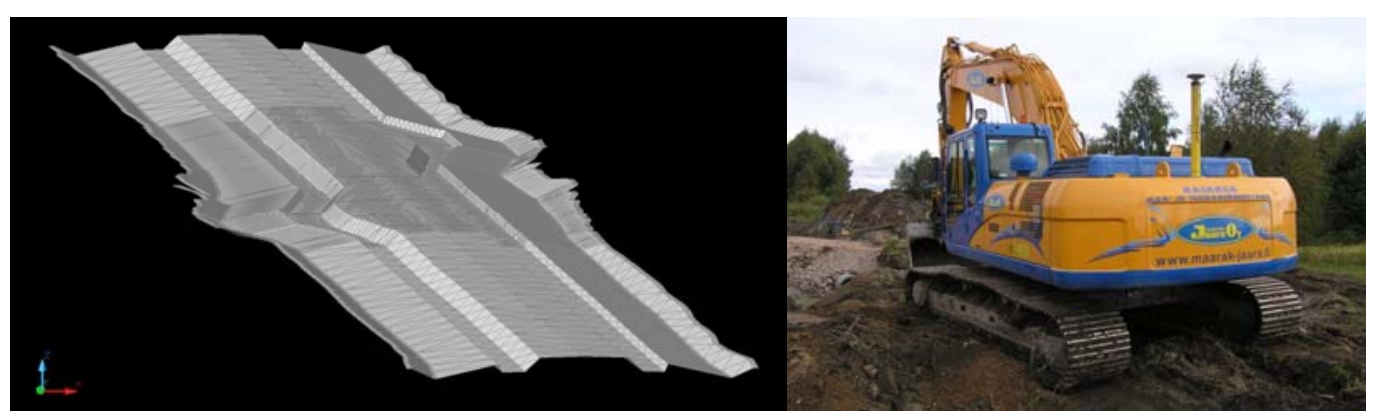

Fig. 17. A 3D machine control model (left), an excavator equipped with the 3D guidance system.

\subsection{Results of the As-Built Measurement Phase}

In addition to traditional total station measurements, the 3D ground-based mobile laser scanning seemed to work well as an As-Built measurement technique. The experiment with the machine control system used showed that the As-Built function works, but in practice it can in many cases be difficult to perform the measurement tasks needed among the other working tasks. For example, most often compaction works need to be first executed before the As-Built measurement phase. Also, operators should be trained so they can understand the significance of this measurement phase as well as the guidance system tolerances needed for different surfaces and structural layers. Several measurement problems and errors were detected concerning the 3D GPR As-Built measurement. The detailed analysis of the GPR results will be reported separately.

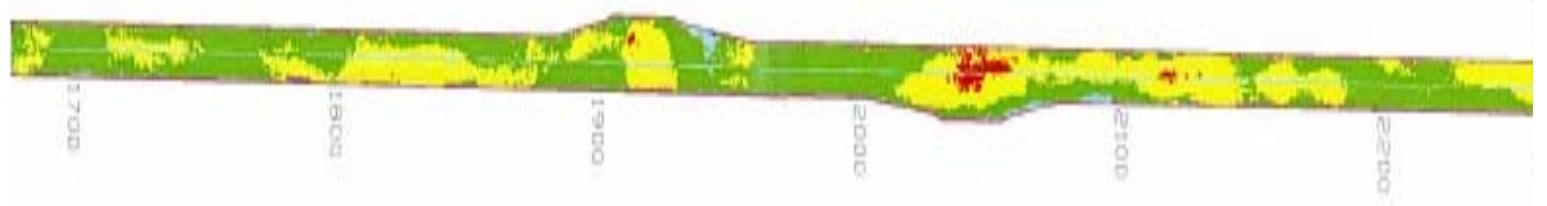

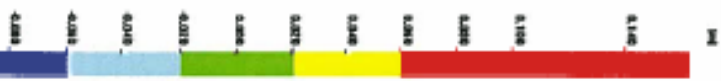

Fig. 18. An example of the 3D mobile laser scanning result - the evenness of the final asphalt surface as 2D color illustration.

\subsection{Results of the Maintenance Phase}

The TYL-E18 Join Venture Project is currently utilizing the 3D mobile laser scanning in their active Design-Build-Utilize-Maintenance project E18 Highway. In a small separate study, the accuracy of measurement of the system was found sufficient to the tolerance requirements by the owner (University of Oulu). However, the question of the accuracy of measurement is complicated and needs further research to understand the question deeper. The measurements were procured for the project through open market competition. This observation verifies the possibilities of 3D surveying methods in the maintenance phases of roads and highways. 


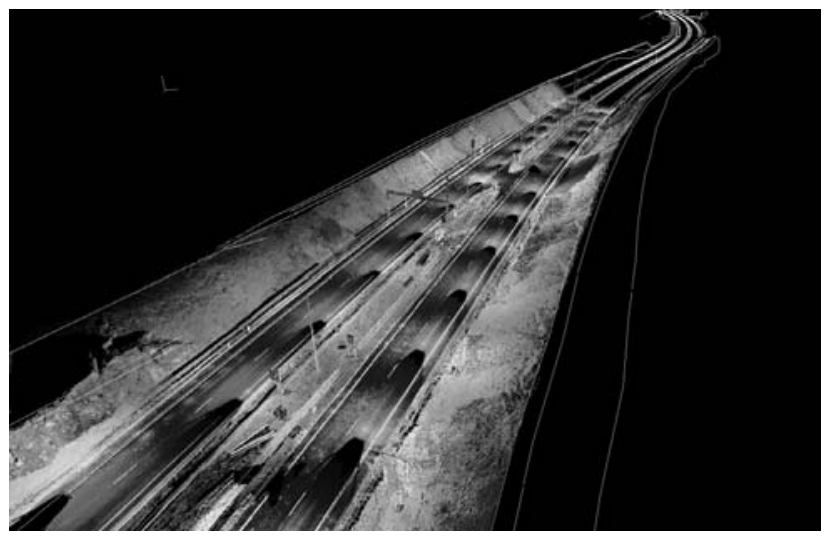

Fig. 19. An example of the 3D mobile laser scanning in the control of the maintenance phase of Design, Build-Maintenance-Operate project in Finland.

\section{CONCLUSIONS}

The report is a general description of the research, how the experiments were carried out and what results were observed. To shorten the presentation, no detailed models and mathematics were presented in the report. Rather, this report provides a high-level idea of the 3D process in road rehabilitation process.

The fundamental idea of automated road rehabilitation is to measure, design and execute all of the possible work tasks using 3D techniques to create, transfer and utilize continuous information models throughout the whole working process. This process can work if each part or phase can be performed accurately, reliably and economically. Measured 3D initial data models enable the optimization of road structures in road design phase and continuous 3D structure and machine control models with 3D guidance systems in machines the execution of efficient construction works. All of the essential information can further be transferred and utilized also during later maintenance phases.

In the project, there was a very strong and productive collaboration with the road owner. The Finnish Road Administration (FRA) developed subphase-specific requirements to speed up the implementation of new technology. The requirements were included in the requests for bids, enabling the actors to present their own implementation solutions as part of their bids. The test project of a $12.5 \mathrm{~km}$ length road gave the companies an opportunity to develop and test automation technology. It is suggested that the key role of road owner is always essential in the development of this type of very large and long-term process such as road construction. It is also suggested that the active development attitude and status of owners is one of the key reasons behind the observation that especially Norway and Sweden in Scandinavia are very advanced in the utilization of the newest 3D methods and tools in road construction. As such, owners are playing the key role in the development of automated 3D processes into road construction.

Digital terrain model created by helicopter-based laser scanning and photogrammetric imaging offers a very good and information rich basis for road design, in which however the technical features of current road design software restrict the utilization of the measured 
information. The digital terrain model measured from helicopter was found to have sufficient accuracy of measurement for the creation of 3D machine control models for realization of construction works. The 3D GPR method shows strong potential as a surveying technique for the measurement tasks of old structural layers and road features. It still needs improvements in measurement accuracy and reliability. Accurate GPR results would enable better utilization of old structures in road rehabilitation design and thus the optimization of new construction works needed.

The creation of 3D machine control models was possible using both of the road design software packages used in the experiments. Many development needs and lacks were however observed concerning most often the development of the labor productivity of road design or the quality control of models. The 3D machine control systems worked very well during construction phases. No clear savings from increased efficiency of construction activities were reported. However, the contractor reported on the many benefits they had observed. In As-Built measurements, the 3D mobile laser scanning system was found, regardless of some measurement errors, to have excellent measurement features relative to the measurement needs of this working phase. In the last 3D GPR experiment for the AsBuilt measurement, however, several measurement problems occurred preventing the final evaluation of this measurement principle.

\section{REFERENCES}

Heikkilä, R. \& Jaakkola, M. \& Saarenketo, T. \& Malaguti, F. (2004) Modelling Information Flows for Automated Road Rehabilitation Process. ISARC'2004, 21st International Symposium on Automation and Robotics in Construction, 21-25 September 2004. Jeju, Korea, pp. 85-93.

Heikkilä, R. (2009) 3D-tietomalleja ja automaatiota hyödyntävän kokonaistoimintaprosessin kehittäminen tieväylien rakenteen parantamiseen - CASE VT4-Haurukylä-Haaransilta (3DROAD) Tutkimus- ja kehittämisprojektin loppuraportti, 77 s. + liitteet.

Heikkilä, R. \& Jaakkola, M. (2006) Automation of Road Construction - the State of the Art in Europe. ISARC'2006, The $23^{\text {rd }}$ International Symposium on Automation and Robotics in Construction, 3-5 October 2006, Tokyo, Japan, pp. 7-10.

JHS154. ETRS89-järjestelmään liittyvät karttaprojektiot, tasokoordinaatistot ja karttalehtijako. Julkisen hallinnon suositus. 34 s.

Hiremagalur, J. \& Yen, K. S. \& Lasky, T. A. \& Ravani, B. (2009) Testing and Performance Evaluation of Fixed Terrestrial 3D Laser Scanning Systems for Highway Applications. Paper NO. 09-1995, Transportation Research Board $88^{\text {th }}$ Annual Meeting. 19 p.

Skibniewski, M. \& Hendrickson, C. (1990) Automation and Robotics for Road Construction and Maintenance. ASCE Journal of Transportation Engineering 116, pp. 448-462.

Tervo, M., \& Perälä, M. \& Pikkarainen, M. \& Niskanen, J. \& Perälä, T. \& Saarenpää, T. (2007) Ylläpidon ja hoidon automaation kehittäminen, toimintamallin testaaminen yhteisalueurakassa - case Kuusamon alueurakka. 